\title{
Migraine Reduction After Transcatheter Closure of Interatrial Septal Defects: Another Brick in the Wall?
}

\section{Migraine Reduction after ASD Closure}

\author{
Mark Reisman, $\mathrm{MD}^{1 *}$, Elizabeth M. Perpetua, DNP2 \\ ${ }^{1}$ Division of Cardiology, Department of Medicine, University of Washington, Seattle, Washington, USA \\ ${ }^{2}$ Division of Cardiothoracic Surgery, Department of Surgery, University of Washington, Seattle, Washington, USA
}

\section{Key Words}

\section{Migraine • Interatrial septal defects \\ Copyright $\odot 2016$ Science International Corp.}

Migraine is one of the most common medical diagnoses, affecting $13 \%$ of adult population, or 1 in 4 households, in the U.S [1]. Migraines frequently occur between 25 and 55 years of age, resulting in major limitations on quality of life and economic opportunity during our most generative years of life. The societal and economical implications include 112 million bedridden days per year and costs exceeding over $\$ 15$ billion due to work loss [2]. Despite their prevalence and burden, migraines remain a sorely underdiagnosed and undertreated disability [1].

In Wilmhurst and colleagues' seminal trial [3], migraine relief was a serendipitous finding in select patients who underwent patent foramen ovale (PFO) closure for decompression illness and stroke. Similar findings in multiple retrospective cohorts [4-6] spurred the field to focus its sights on PFO closure in the setting of cryptogenic stroke.

A provocative, albeit opaque, relationship emerged between right-to-left shunt (RLS), migraines, and PFO closure. Cryptogenic stroke patients were twice as likely to have a history of migraine headaches as

Fax +1 2037853346

E-Mail: jshd@scienceinternational.org

http://structuralheartdisease.org/

\author{
(C) 2015 Journal of Structural Heart Disease \\ Published by Science International Corp. \\ ISSN 2326-4004 \\ Accessible online at: \\ http://structuralheartdisease.org/
}

those without PFO (27\% versus $14 \%$, respectively) [7]. PFO was seen more frequently in people with migraine with aura than in age- and sex-matched controls ( $47 \%$ versus $17 \%$, respectively) [8]. Headache activation after atrial septal defect (ASD) closure, specifically with Nitinol-based devices (Amplatzer), was reported, encouraging further investigation $[9,10]$. All that was necessary was a prospective clinical trial, designed to account for the placebo effect and adjudicated by migraine neurologists: the Migraine Intervention with StarFlex Technology (MIST) trial [11].

Many interventional cardiologists were optimistic; we saw dramatic life changes in our patients. Otherwise healthy individuals with cryptogenic stroke who were debilitated, not by residual neurological defects, but by crippling migraine headaches, returned to our clinics months later reporting life-altering improvements in headache frequency and severity.

The construct collapsed with a negative trial, critiqued for its design, operators, patient selection, marginally effective device, and overreaching endpoint. Perhaps we should have predicted the study outcome based solely on the ubiquitous nature of headache. We did not have a pathologic footprint to track, which remains true to this day. It was known that migraine is an elusive target for phar-

* Corresponding Author:

Mark Reisman, MD

University of Washington Medical Center

Division of Cardiology

1959 NE Pacific Street, Box 356171 Seattle, WA 98195, USA

Tel.: +1 206598 3171; Fax: +1 206598 3037; E-Mail: reismanm@uw.edu 
macological therapy; this held true for devices as well. These challenges culminated in the termination of MIST II.

Despite these setbacks, investigators have continued to explore the closure of interatrial septal defects and migraine relief. The study by Tayaka and colleagues [12] provides another link between the presence of RLS and migraines. Their data support the reports of a higher prevalence (56\%) of migraines in patients with RLS, but also suggest a high prevalence in patients with ASDs (29\%). While not an entirely novel finding, the relationship behind ASD and migraines has not been the emphasis of investigation. This prospective trial adds little to the body of evidence of nonrandomized PFO closure and migraine relief, but it demonstrates that there is potentially an interaction with ASDs, and their closure may impact headaches.

The study by Tayaka et al addresses several gaps of previous trials. The endpoint assessment of headache was based, correctly, on a neurologist's evaluation. The four-category reporting system for headache severity and frequency provides quantification consistent with the real world expectation of improvement. Follow-up was well documented, along with the response to clopidogrel, which may play a role in migraine relief. Notably, relief persisted beyond the termination of clopidogrel at 1 month.

The trial exhibits well-described limitations of nonrandomized clinical studies without control groups or blinding. The assessment of pharmacologic therapy for migraine headache was not described, and the evaluation tools did not include a headache diary. These omissions are especially important given that improvement, and specifically complete resolution, of migraines was high in all patients. Migraine relief was highest in patients after PFO closure but also high after ASD closure, with 15 of 20 patients improving and nearly half of these patients reporting complete resolution. The mean post-procedure follow-up for patients after ASD closure was half of that after PFO closure (22 versus 44 months, respectively). A longer follow-up period overall may have decreased the likelihood that relief was due to placebo and would have been beneficial to evaluate the underlying relationship between RLS and headache.
Tayaka and colleagues did not specify key methods and procedures, including the imaging protocol for evaluating interatrial septal defect anatomy and RLS. Thus, procedural success was not defined. Related procedural results were undescribed, namely the presence and quantitation of post-procedural residual shunt in patients after ASD closure, particularly in those without improvement of migraine. These descriptions and data are critical to correlating closure with relief, and particularly essential in the study of a clinical syndrome with placebo effects that may exceed $20 \%$ [13].

A large, randomized clinical trial aimed to overcome these limitations and provide a definitive foundation for evidence-based PFO closure for migraine headache. The Prospective, Randomized Investigation to Evaluate Incidence of Headache Reduction in Subjects with Migraine and PFO Using the Amplatzer PFO Occluder to Medical Management (PREMIUM) trial was presented in June 2015 at the American Headache Society [14]. PREMIUM was the third trial to examine migraine relief with PFO closure, the second to use the Amplatzer device, and the second to use sham surgery as a control. The primary endpoint of $50 \%$ reduction in migraine was not met; there was no difference in migraine attack frequency in patients who underwent closure $(n=117)$ versus patients randomized to sham and medical therapy $(n=103)$. Among migraineurs with aura, however, those in the closure group had a higher rate of complete remission than those in the sham group (10.8\% versus $1.5 \%$, $p=0.02$ ).

These results are consistent with the compelling body of literature demonstrating migraine relief after PFO closure in the subset of patients who have migraine with aura. The high frequency of large RLS in these patients [8], and the high rate of migraine relief and even complete remission in patients after PFO closure [12,14], suggest that RLS has a role in migraine pathogenesis. However, study findings must be cautiously interpreted before changing clinical practice. Currently, there are no studies actively enrolling for PFO closure in patients with headache, and it is purported that the U.S. Food \& Drug Administration may want another trial. Fundamental questions for future investigation remain.

- In the absence of a pathologic signature, can we refine 
our study group in subsequent randomized trials?

- Based on the safety of PFO devices [15], is it reasonable to address a cohort with headaches less recalcitrant than migraine?

- Can we define a PFO or RLS headache? Are there other substrates lacking chemical conversion by the pulmonary circulation in these patients?

In conclusion, Tayaka and colleagues have deepened our knowledge base. However, investigators must expand our inquiry to the basic science linking right-to-left circulation and headaches. Migraines are one of the most debilitating diseases, and, if a safe and simple car- diac procedure is to be provided in hopes of improving our patient's health and quality of life in their prime, it is imperative that we cement the construct between migraine, RLS, and this therapy.

\section{Conflict of Interest}

The authors have no conflict of interest relevant to this publication.

\section{Comment on this Article or Ask a Question}

\section{References}

1. Lipton RB, Stewart WF, Diamond $S$ Diamond ML, Reed M. Prevalence and burden of migraine in the United States: data from the American Migraine Study II. Headache. 2001;41:646-657. DOI: 10.1046/j.15264610.2001.041007646.x

2. Stewart WF, Lipton RB, Simon D. Work-related disability: results from the American migraine study. Cephalalgia. 1996;16:231238; discussion 215. DOI: 10.1046/j.14682982.1996.1604231.x

3. Wilmshurst PT, Nightingale $S$, Walsh KP, Morrison WL. Effect on migraine of closure of cardiac right-to-left shunts to prevent recurrence of decompression illness or stroke or for haemodynamic reasons. Lancet. 2000;356:1648-1651. DOI: 10.1016/ S0140-6736(00)03160-3

4. Reisman $M$, Christofferson RD, Jesurum J, Olsen JV, Spencer MP, Krabill KA, et al. Migraine headache relief after transcatheter closure of patent ovale. J Am Coll Cardiol. 2005;45:493-495. DOI: 10.1016/j. jacc.2004.10.055

5. Post MC, Thijs V, Herroelen L, Budts WI. Closure of a patent foramen ovale is associated with a decrease in prevalence of migraine. Neurology. 2004;62:1439-1440. DOI: 10.1212/01.WNL.0000120756.25236.37

6. Schwerzmann $M$, Nedeltchev $K$, Lagger $F$, Mattle HP, Windecker $S$, Meier B, et al. Prevalence and size of directly detected patent foramen ovale in migraine with aura. Neurology. 2005;65:1415-1418. DOI: 10.1212/01.wnl.0000179800.73706.20
7. Lamy C, Giannesini C, Zuber M, Arquizan C, Meder JF, Trystam D, et al. Clinical imaging findings in cryptogenic stroke patients with and without patent foramen ovale: the PFO-ASA Study. Atrial Septal Aneurysm. Stroke. 2002;33:706-711. DOI: $10.1161 / \mathrm{hs} 0302.104543$

8. Azarbal B, Tobis J, Suh W, Chan V, Dao C, Gaster R. Association of interatrial shunts and migraine headaches: impact of transcatheter closure. J Am Coll Cardiol. 2005;45:489-492. DOI: 10.1016/j. jacc.2004.09.075

9. Rodés-Cabau J, Molina C, Serrano-Munuera C, Casaldáliga J, Alvarez-Sabin J, Evangelista $A$, et al. Migraine with aura related to the percutaneous closure of an atrial septal defect. Catheter Cardiovasc Interv. 2003;60:540-542. DOI: 10.1002/ccd.10713

10. Wertman B, Azarbal B, Riedl M, Tobis J. Adverse events associated with nickel allergy in patients undergoing percutaneous atrial septal defect or patent foramen ovale closure. J Am Coll Cardiol. 2006;47:1226. DOI: 10.1016/j.jacc.2005.12.017

11. Dowson A, Mullen MJ, Peatfield R, Muir K, Khan AA, Wells $C$, et al. Migraine Intervention With STARFlex Technology (MIST) Trial: a prospective, multicenter, double-blind, sham-controlled trial to evaluate the effectiveness of patent foramen ovale closure with STARFlex septal repair implant to resolve refractory migraine headache. Circulation. 2008;117:1397-1404. DOI: 10.1161/CIRCULATIONAHA.107.727271
12. Takaya Y, Akagi T, Kijima Y, Nakagawa K, Kono S, Deguchi K, Sano S, Ito H. Resolution of Migraine After Transcatheter Closure of Atrial Communication. Structural Heart Disease. 2016;2:102-107. DOI: 10.12945/j.jshd.2016.010.15

13. van der Kuy PH, Lohman JJ. A quantification of the placebo response in migraine prophylaxis. Cephalalgia. 2002;22:265-270. DOI: 10.1046/j.1468-2982.2002.00363.x

14. Charles A for the PREMIUM Investigators. Late breaking trial: Prospective, Randomized Investigation to Evaluate Incidence of Headache Reduction in Subjects with Migraine and PFO Using the Amplatzer PFO Occluder to Medical Management. June 26, 2015. Presentation for the 57th Annual American Headache Society. Washington DC.

15. Carroll JD, Saver JL, Thaler DE, Smalling RW, Berry S, MacDonald LA, et al. Closure of patent foramen ovale versus medical therapy after cryptogenic stroke. J Am Coll Cardiol. 2013;368:1092-100. DOI: 10.1056/ NEJMoa1301440

Cite this article as: Reisman $M$, Perpetua EM. Migraine Reduction After Transcatheter Closure of Interatrial Septal Defects: Another Brick in the Wall? Structural Heart Disease. 2016;2(5):231-233. DOI: http://dx.doi. org/10.12945/j.jshd.2016.012.15 